\title{
RESPOSTA DOS TECIDOS MOLES AO MATERIAL DE SUTURA intervenções na cavidade oral de cobaias
}

\section{SINOPSE}

Pesquisa destinada a avaliar o comportamento dos fios de sutura na cavidade oral (transfixação na língua). Materiais empregados multinylon trançado e algodão, ambos 4.0

\section{INTRODUCXAO}

O principal objetivo da pesquisa é comparar os resultados obtidos nas suturas das feridas da cavidade oral, com o fio de algodão multinylon, considerando as condições das Clínicas Populares de Assistência Social, e o atendimento a pacientes nos Ambulatórios da Faculdade, onde o em. prego de material de baixo custo os altamente relevante, considerada a igualdade de resultados.

indiscutível e provado cientificamente a necessidade da síntese dos tecidos moles após intervenções cruentes de qualquer tipo, para:
Silvina Terezinha Lima Grossi *

Onofre Francisco de Quadros **

Gaspar Soares Brandão ***

Hardy Ebling

1.1 - Manter os tecidos moles coaptados sobre o osso, contribuindo para a aceleração e normalidade do processo de reparo;

1.2 - Prevenir hemorragias pós-operatórias;

1.3 - Contribuir para a formação e manutenção de bom coágulo sangüíneo evitando a infeç̧ão do mesmo;

1.4 - Diminuir a dor pós-operatória, em especial aquela provocada pela exposição óssea;

1.5 - Evitar a penetração de corpos estranhos na ferida, lisando o coágulo ou infectando-o.

\section{TRABALHO EXPERIMENTAL}

Os experimentos para a avaliação cuidadosa das reações orgânicas que se processam no reparo das feridas e o comportamento do material em pregado para a contenção dos tecidos, são raros, em relação a cavidade oral. Objetivando o assunto, Lo-

\footnotetext{
* Prof. Assistente na Faculdade de Odontologia, UFRGS

* Prof. Asssistente na Faculdade de Odontologia, UFRGS

*** Prof. Titular na Faculdade de Odontologia, UFRGS

**** Prof. Titular na Faculdade de Odontologia, UFRGS.
} 
randi, Ebling e Barbachan, 1965 realizaram investigação cuja conclusão foi a seguinte: «Tudo se passa como se o multinylon não fosse reabsorvido, ambos sem infiltração. Os outros tipos de fios apresentam infiltraça linfoplasmocitária discreta aos trinta dias da experiência» (1).

Postleth Wait et alli, 1959 (2) cita o considerável interesse sobre as reações teciduais à materiais ou fibras sintéticas. Sugerem o emprego de tubo de material sintético como substituto de vasos sanguíneos. Os estudos no que se refere as suturas cirúrgicas, têm sido pouco numerosos.

Savchenko, 1955 (3) informa que a reação inflamatória e sua duração foram menores quando empregou sutura à fio de seda.

Sewell, Wiland e Crayer, 1955 (4) concluiram que no rato a reação inicial após 5 dias da intervenção cirúrgica a qualquer fio de sutura de origem ovina ou bovina é inflamatória.

Lilly, 1968 (5) descrevendo seus experimentos declara «a resposta dos tecidos orais a novos materiais de sutura foi estudada histopatologicamente em cães que receberam antibioticoterapia sistêmica. Os materiais de sutura monofilamentosos nylon, catgut, aço níquel e cromo - causam nesses casos reações menos severas do que os materiais multifilamentosos como seda trançada, fibra de poliester, algodão e linho.
Estes experimentos indicam que a resposta do tecido oral em relação a natureza física do material de sutiu. ra, e do emṕprego de antibióticos sistêmicos não alteram apreciavelmente a resposta aos vários materiais de sutura».

A colaboração de Drown e Brenn, 1968 (5) para corar secções de tecido demonstra-nos interstícios celulares contendo partículas de material de sutura multifilamentosas. Lembra ainda que a variação na resposta dos tecidos, quando na presensa de boctérias pode ser devida a diferenças sistêmicas.

Aterbury, 1968 (6) escreve: «enquanto não for possível se determinar com segurança o calibre exato e a variedade do material de sutura absorvível e não absorvível a ser usado em todos os procedimentos cirúrgicos orais, a preferência do cirurgião deverá ser para material de sutura que desenvolva menor reaçâo tecidual.

\section{MATERLAIS}

3.1 - Animais: 34 cobaias de mais ou menos cem (100) dias, de ambos os sexos, de acordo com a disponibilidade.

3.2 - Fios: multinylon 4.0 e algodão 3.0 ou $n^{\circ} 40$.

3.3 - Instrumental : bisturi Bard Parke, lâmina no 11; tesouras cirúrgicas retas e curvas; pinças porta agulha de Mathieu $13 \mathrm{~cm}$; agulhas para sutura $n^{\circ} \mathrm{G}-$ 504-14; gase; 


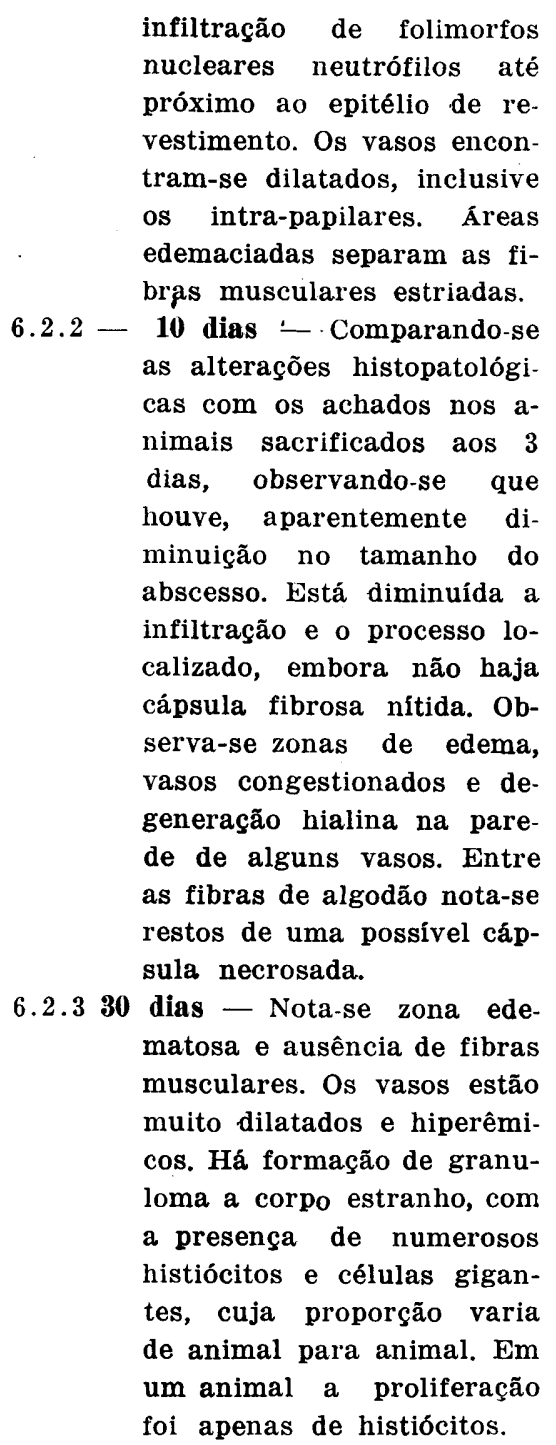

\section{SUMULA DO S RESULTADOS}

7.1 - Multinylon: 0 material é expulso em alguns casos, res- tando inflamação crônica com destruição dos feixes de fibras musculares estriadas, envolvidas no processo. Se a sutura for superficial, engloban. do pouca porção de fibras musculares e não houve deiscência da sutura cirúrgica resulta reação inflamatória, manifestando, de início, por abscesso agudo que com o passar do tempo evolui para crônico, terminando em granuloma a corpo estranho. $O$ processo final é mais ou menos rico em células gigantes, por motivo que não conseguimos determinar.

7.2 - Algodão: Da aplicação do fio igualmente resulta abscesso agudo e ampla infiltração em praticamente todo o campo, respeitada apenas a faixa justa epitelial. Com demora na remoção da sutura, há o aparecimento de numerosas placas bacterianas, entre as células características do pro cesso inflamatório o que lentamente regride com perda df fibras musculares estriadas.

\section{SYNOPSIS}

Research in order to evaluate the behaviour of suture threads into oral cavity (Transfixation in tongue).

Materials employed were braided multinylon and cotton, both 4.0. 


\section{REFERENCIAS BIBLIOGRÁFICAS}

1. ATTERBURYRA, et alii. - Suture material; an important accessory in the art of oral surgery. Dent. Dig., 74:258-61, jun. 1968.

2. LILLY, G.E. et alii. - Reaction of oral tissues to suture materials. Oral Surg, $26: 592-9$, oct. 1968.

3. LORANDI, Cesar S. - Reação aos diferentes tipos de sutura; observação em língua de rato. An. IX Cong. Odont. bras., II Cong. Int. Odont., Rio de Janeiro, p.256-7, 25 a 31 de jul. 1965.

4. POSTLETH, R. W. \& SCHAUBLE, J. F. -- An evolution of surgical suture material. Surg. Gynecol. Obstet., 108:555-6, 1959.

5. SAVCHENKE, V.E. - Polyamide fisch line sutures. Dent. Abstr., 6: 600-61, 1961.

6. SEWELL, W.R. et alii. - A new method of comparing sutures of ovines catgut with sutures of bovines catgut; in three species. Surg. Gynecol. Obstetr., 100:483-94, 1955.

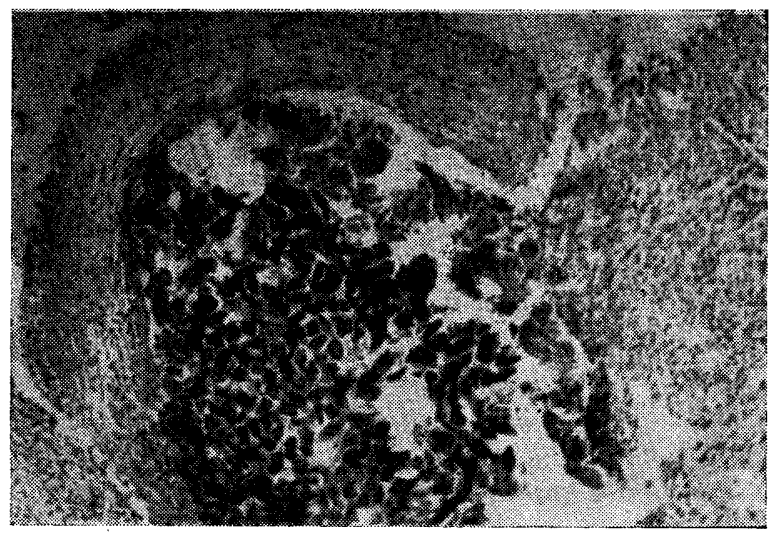

Multinylon-3495-3 dias

R. Fac. Odont. P. A.

$13 / 14: 15-22,1971 / 1972$ 


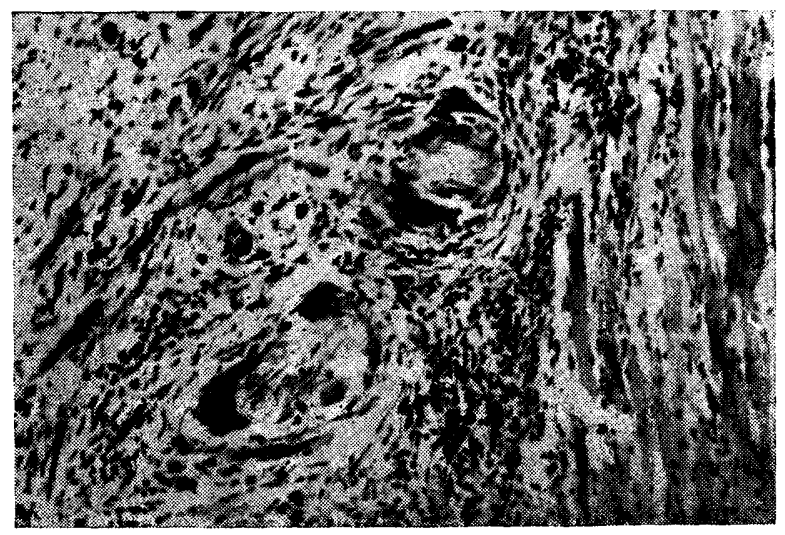

Muitinylon-3522-30 dias

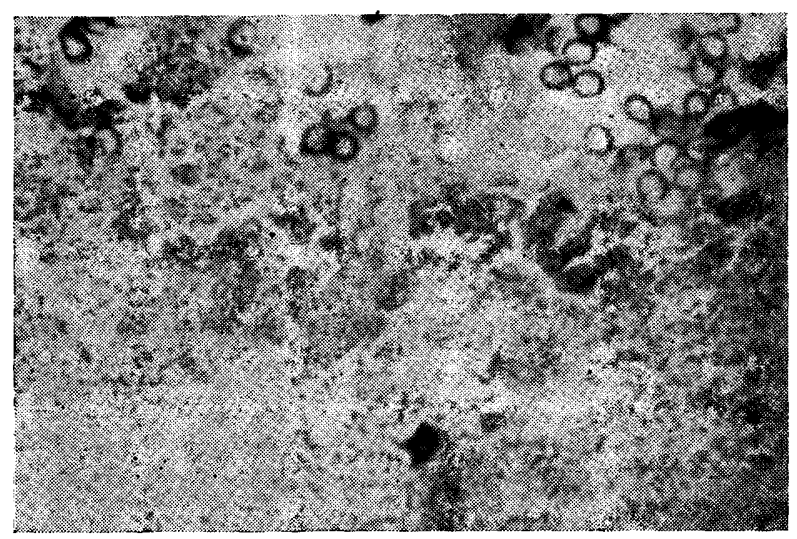

Multinylon-3495-3 dias

R. Fac. Odont. P. A. 


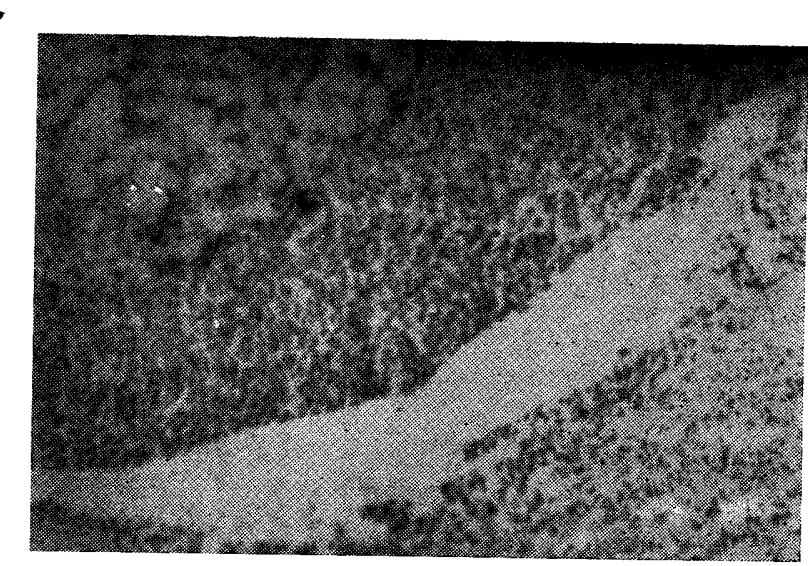

Algodão-3483-3 dias

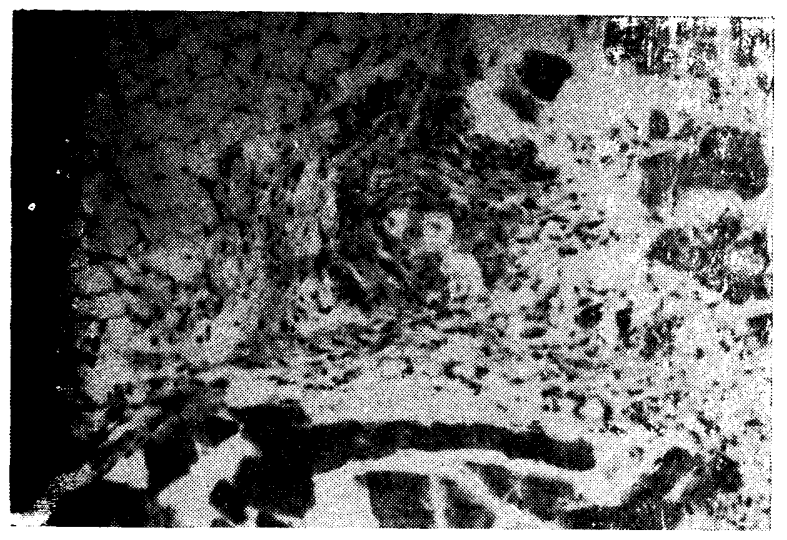

Algodão-3514-3515-3516-30 dias

R. Fac. Odont. F. A. 


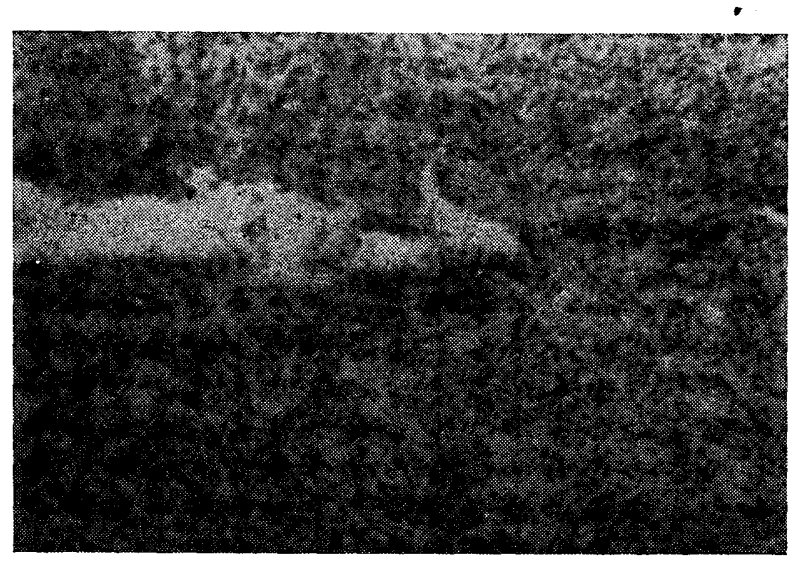

Multinylon-3458-3 dias

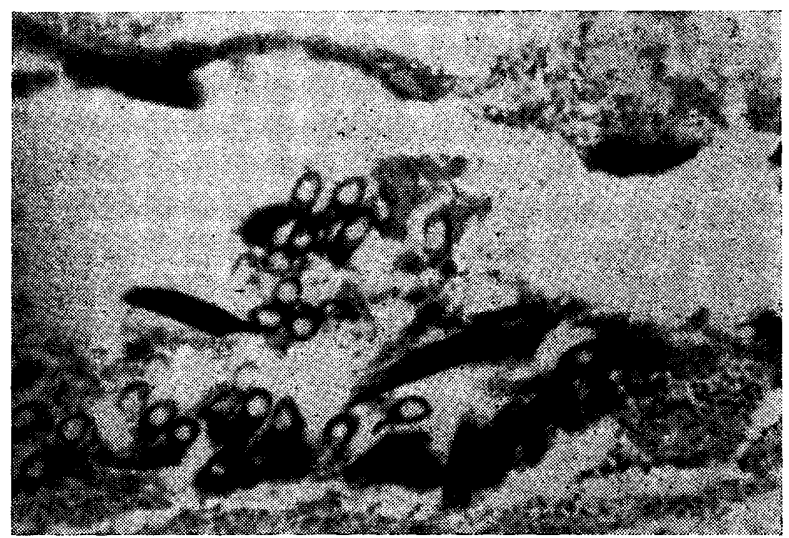

Multinylon-3458-3 dias

R. Fac. Odont. F. A.

$13 / 14: 15-22,1971 / 1972$ 